\title{
Spatial Assessment of a Biocriteria Applied to Texas Tidal Streams
}

\author{
James M. Tolan ${ }^{1}$ and Janet M. Nelson ${ }^{2}$ \\ ${ }^{1}$ Texas Parks and Wildlife Department, 6300 Ocean Drive, NRC 2501, Corpus Christi, TX 78412, USA
}

${ }^{2}$ Texas Parks and Wildlife Department, 4200 Smith School Road, Austin, TX 78744, USA

Correspondence should be addressed to James M. Tolan; james.tolan@tpwd.state.tx.us

Received 2 May 2013; Revised 20 August 2013; Accepted 24 August 2013

Academic Editor: Henry M. Page

Copyright (C) 2013 J. M. Tolan and J. M. Nelson. This is an open access article distributed under the Creative Commons Attribution License, which permits unrestricted use, distribution, and reproduction in any medium, provided the original work is properly cited.

\begin{abstract}
This study reports on a derived multivariate method for assessing ecosystem health within tidally influenced portions of river basins and coastal basins. These tidally influenced areas are highly productive transitional areas which serve as important nursery areas for many fish and shellfish species. Numerous Texas tidal streams under varying degrees of anthropogenic stressors were analyzed jointly with this new, standardized methodology. Physical and chemical constituents of the tidal systems, as well as their resident nekton communities, were compared with nonparametric ordination techniques in order to uncover a biocriteria that might have general applicability over large spatial scales. All of the tidal stream communities were dominated by only a few taxa that each displays tremendous euryhaline/physiological tolerances, and these abilities allow taxa utilizing tidal streams to adapt to a wide variety of environmental stressors. The absence of any clear connections between degraded water-bodies and any impaired nektonic communities should not automatically be viewed as a constraint inherent to the techniques of the methodology presented, but rather a verification that impaired tidal streams are not that common of an occurrence along the Texas coast, at least not when using nekton communities as the degradation indicator.
\end{abstract}

\section{Introduction}

Tidal streams are highly productive transitional areas found in the mixing zones between the freshwater of the rivers and the increased salinities found within the estuary. Tidal streams also serve as important nursery areas for many fish and shellfish species, and a number of species have been shown to actively recruit to these important habitats [1-4]. Routine monitoring of several tidally influenced segments throughout the state of Texas has revealed that water quality standards are not currently being met (Texas Commission on Environmental Quality (TCEQ), 2010 [5]). Listed tidal segments, routinely cited as having increased bacterial loads and depressed dissolved oxygen measurements, and these excursions of low dissolved oxygen waters could have a detrimental effect on the early life history stages of finfish and shellfish utilizing these nursery areas. Water quality management of these areas has been difficult because currently there are no statewide criteria for assessing tidally influenced waterbodies, and these systems are naturally quite variable over time and space [6].

Inclusion on this impaired waterbody list initiates the total maximum daily load (TMDL) process. As a first step, it is necessary to assess the water body and determine if the impairment is genuine and, if so, whether or not it is caused by pollutants. This task is more difficult with respect to tidally influenced portions of streams, because currently there is no standardized methodology for performing this assessment. A potential method, based on multivariate community-level assessment, was initially developed for five tidal segments [7], with the ultimate goal of uncovering biological evaluation criteria (biocriteria) for tidal streams that could have applicability over large spatial scales. To date, the many unclassified tidally influenced coastal streams within the state are presumed to have a High Aquatic Life Use and the corresponding dissolved oxygen criteria (minimum average 


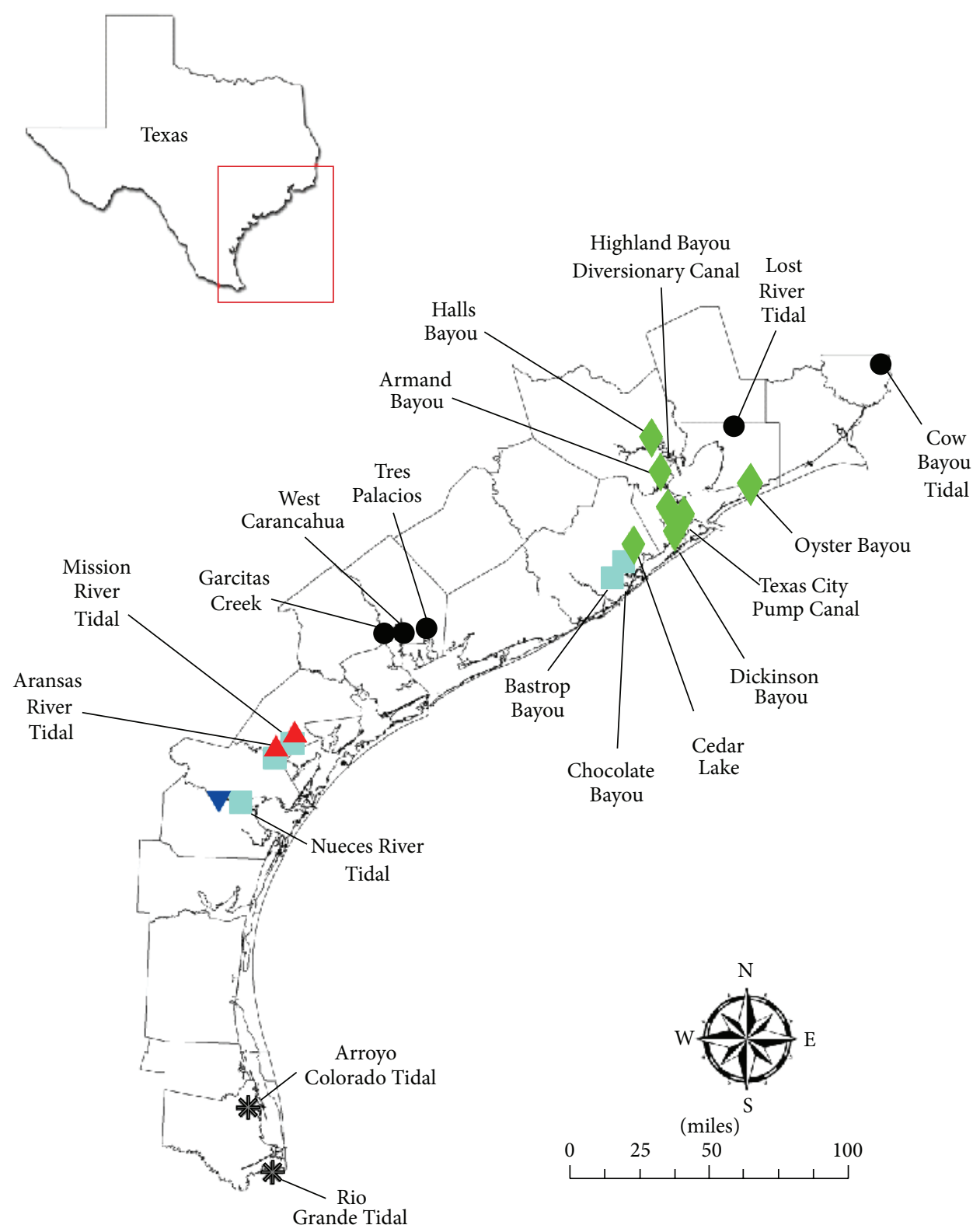

FIGURE 1: Map of tidal stream locations used for the coastwide assessment methodology, color coded by study: green = Texas Commission on Environmental Quality Studies (TCEQ-1 and TCEQ-2), light blue = Water Quality Study (WQS), black = Use Attainability Analysis Study $($ UAA), dark blue = Nueces Trawl Survey (NTS), red = Mission/Aransas Study (MA); grey = Lower Coast Studies (LCS).

of $4.0 \mathrm{mg} / \mathrm{L}$ DO over a 24 hour period, and a daily minimum of $3.0 \mathrm{mg} / \mathrm{L} \mathrm{DO}$ ) have been used to evaluate their attainment [8]. Biologically based evaluation criteria provide additional information on community composition, overall health, and the abundance of the various trophic levels and attempt to tie those to the physical habitats in which they live [9-11]. The purpose of this study was to compile historical datasets from Texas tidal streams under varying degrees of anthropogenic stressors and analyze them jointly with this new, standardized methodology. With a wide array of ecological conditions present within this analysis, one goal of the study was to uncover biocriteria that could have general applicability over large spatial scales.

\section{Methods and Materials}

2.1. Study Locations. Five of the six studies that formed the basis of this work are fully detailed in Tolan [12] and are shown in Figure 1. Briefly, the TCEQ studies sampled water quality, water chemistry, and nekton in Oyster Bayou, Dickinson Bayou, Texas City Pump Canal, Highland Bayou Diversionary Canal, and Cedar Lake Creek from June 1991 to September 1993 (TCEQ-1; [13]) and Armand Bayou and Halls Bayou from April 2002 until June 2003 (TCEQ-2; L. Broach, Texas Commission on Environmental Quality, unpublished data). Alan Plummer and Associates [14] sampled water quality and nekton from the tidal portions of 
the middle coast (Nueces, Aransas, and Mission Rivers) and upper coast (Bastrop and Chocolate Bayous) during a single summer season in 1995. This study is referred to as the water quality study (WQS). A second study on the Nueces River (Texas Parks and Wildlife Department (TPWD), unpublished data) measuring water quality and otter trawl-only nekton collections took place from October 1996 to November 2001 and will be identified as the Nueces Trawl Survey (NTS). Additional TPWD studies [15, 16] involved water quality, water chemistry, and nekton collections from the tidal portions of Tres Palacios River, Garcitas Creek, the west fork of the Carancahua River, Lost River, and Cow Bayou from April 2003 to November 2004 are referred to as the use attainability analysis study (UAA). Similar work conducted by TPWD on the tidal portions of the Mission and Aransas Rivers (MA) took place from March 2008 to November 2009 [16]. Three studies concentrated efforts along the lower coast (Arroyo Colorado and Rio Grande) tidal segments from May 1989 to December 2003 are referred to as the lower coast studies (LCS).

2.2. Nekton Collections. The level of effort in the nekton collections differed greatly amongst the various studies, especially with respect to the equipment used within each stream. These differences are outlined in Table 1. For each gear, individual replicates within a stream were pooled, and total nekton collections were standardized to reflect catchper-unit-effort (linear shoreline distance for nearshore seines; trawl time for midchannel otter trawls).

2.3. Assessment Methodology. The multivariate methodology for assessing ecosystem health and assigning site-specific uses and criteria within tidally influenced portions of river basin and coastal basin waters relies heavily on the nonparametric ordination techniques and are outlined by Contreras et al. [7]. Nonmetric multidimensional scaling (MDS) procedures were used to identify the configurations of the different datasets (e.g., biological, physiochemical, habitat, etc.), and any distinction among streams, in terms of their biologic communities, as well as any physical/chemical property differences, was first established. The goal of the MDS is to assess any agreement between the biological "picture" and the more traditional physical and chemical "pictures." Spearman's rank correlation was used to quantify the degree of agreement between the natural separation of the "biological" and the "physical and/or chemical" measurements.

Any significant differences among the studies were evaluated with the analysis of similarity (ANOSIM) procedure [17], and those results are graphically displayed with MDS means configurations at $\alpha$ levels of 0.05 and 0.10 . The ANOSIM procedure is valid for not only the biological communities, but also for the physical and chemical constituents as well. The variables (i.e., nekton taxa) most responsible for the separations seen in the ANOSIM are identified with the similarity percentages (SIMPER) procedure. The biological communities are further assessed with the Average Taxonomic Distinctness measure [17]. From this, a suite of indicator taxa can be identified, and their sensitivity to variability in the physical and chemical datasets assessed. Core metrics that include information about the taxonomic breadth of the study locations can then be developed. The threshold (biocriteria) for discriminating among impaired and unimpaired conditions provides the basis for the assessment.

The goal of this study was to apply the aforementioned multivariate techniques to a number of historical datasets collected from varying degrees of "impacted" tidal streams and determine to what extent the biological communities can be used to determine biocriteria within tidally influenced segments. As most of these datasets were collected before Aquatic Life Use designations were applied to tidally influenced segments, each of them then, by default, is considered to have a "High" designation within the context of this metaanalysis.

\section{Results}

Due to varying amounts of sampling effort among the studies, the following spatial comparisons of water quality, water chemistry, and biological communities are limited to summer index periods only, as sampling efforts were most uniform during this season. Surface water quality and chemistry measurements are compared to seine collections, as this gear records nekton from the surface margins of tidal streams. Bottom water quality measurements are compared to the otter trawl collections, as this gear samples nekton from the middle of the tidal stream.

3.1. Physical Properties. Surface measurements of routine field parameters (Table 2) are displayed in their MDS configurations in Figure 2. While the ANOSIM test revealed that there were significant differences among the physical characteristics of these different studies (Global $R=0.086$, $P<0.007)$, there is a great degree of overlap that cuts across any latitudinal gradient along the coast (Figure 2(a)). The between-study pairwise comparisons revealed that the greatest degree of differences in surface water collections were found between the lower coast and the studies on the upper coast of both the UAA (which included the most geographic northern tidal locations of Lost River and Cow Bayou; $R=0.933, P<0.001$ ) and the collections by TCEQ (including numerous tidal streams around the Galveston Bay area; $R=0.919, P<0.001$, see Figure 3). These uppercoast/lower-coast distinctions were not consistent though, as the Mission-Aransas Study (MA) was statistically similar to all of the studies on the upper coast. In each case, the parameter most influential in separating out the groups of stations within each of these studies was salinity (Figure 2(b)). Temperature and $\mathrm{pH}$ readings were much less influential in the MDS configuration, as were measures of dissolved oxygen concentrations (recorded as either $\mathrm{mg} / \mathrm{L}$ or percent saturation values). While all of the data used for this particular configuration was collected during the summer season, and despite low dissolved oxygen conditions being evident even in the surface waters, mean dissolved oxygen readings were generally above the threshold value for tidal streams with 
TABLE 1: Summary of the gear specifications used each of the studies used for the Coast Wide assessment methodology. Study designations follow Figure 1. Seine net size in feet; mesh size in square inches; seine type either a straight seine or bag seine (bag size is inset); total shoreline length in feet. Otter trawl net size in feet, mesh size and cod end insert size in inches, trawl time in minutes.

\begin{tabular}{|c|c|c|c|c|c|c|c|c|c|c|}
\hline \multirow{2}{*}{ Study } & \multicolumn{5}{|c|}{ Nearshore seine } & \multicolumn{5}{|c|}{ Midchannel trawl } \\
\hline & Net size & Mesh size & Seine type & Replicates & Shoreline length & Net size & Mesh size & Cod end insert & Trawl time & Replicates \\
\hline TCEQ-1 & $15 \times 4$ & 0.125 & Straight & 5 & 125 & 10 & 1 & 0.25 & 5 & 4 \\
\hline TCEQ-2 & $15 \times 4$ & 0.187 & Straight & 5 & 125 & 10 & 1 & 0.25 & 5 & 4 \\
\hline \multirow{2}{*}{ WQS } & $15 \times 5$ & 0.187 & Straight & * & 133 & & & & & \\
\hline & $30 \times 6$ & 0.125 & $\operatorname{Bag}(6 \times 6)$ & * & 180 & 10 & 1 & 0.20 & 5 & 3 \\
\hline \multirow{2}{*}{ UAA } & $30 \times 8$ & 0.187 & Straight & $<3$ & 125 & & & & & \\
\hline & $10 \times 6$ & 0.187 & Straight & $<6$ & 125 & 10 & 1 & 0.20 & 5 & 3 \\
\hline MA & $30 \times 8$ & 0.187 & Straight & $<3$ & 125 & 10 & 1 & 0.20 & 5 & 3 \\
\hline NTS & - & - & - & - & - & 10 & 1 & 0.20 & 5 & 3 \\
\hline LCS & $20 \times 4$ & 0.125 & $\operatorname{Bag}(4 \times 4)$ & 3 & 75 & 20 & 0.75 & 0.25 & 10 & 3 \\
\hline
\end{tabular}

${ }^{*}$ Seine effort designed to cover between 2,000 and 2,700 square feet, not reported in terms of replicates.
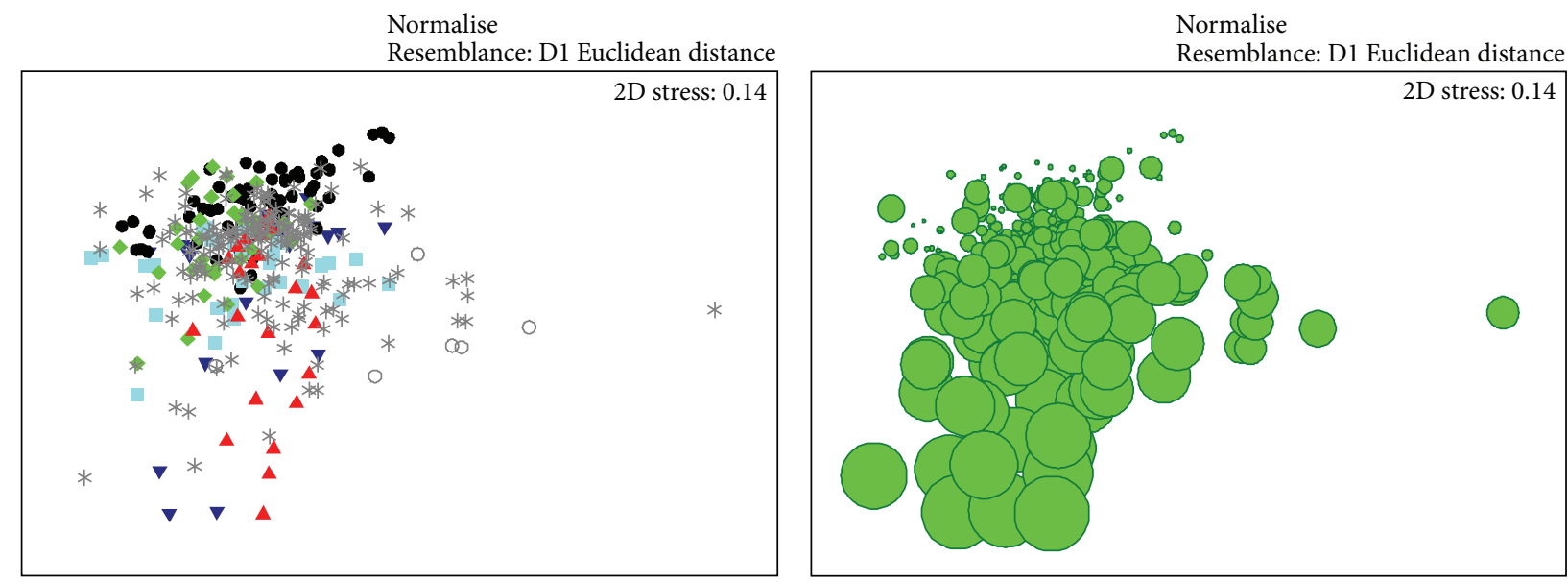

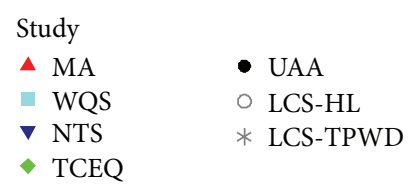

(a)

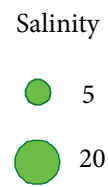

20

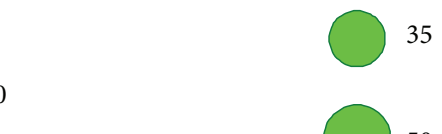

(b)

Figure 2: Multidimensional scaling ordination of the tidal stream locations, labeled by study; (a) based on surface measurements of routine Field parameters; and (b) overlaid with individual salinity measurements.

a High Aquatic Life Use designation. Mean dissolved oxygen readings ranging from a supersaturated high of $15.23 \mathrm{mg} / \mathrm{L}$ $( \pm 3.77 \mathrm{mg} / \mathrm{L})$ in the Arroyo Colorado to a low of $4.77 \mathrm{mg} / \mathrm{L}$ $( \pm 1.08 \mathrm{mg} / \mathrm{L})$ in Cedar Lakes.

3.2. Chemical Properties. Water chemistry measurements (Table 3) were not collected from either the LCS, WQS, or NTS studies; therefore, the analysis of these parameters includes only the MA study, the historical TCEQ datasets, and the initial UAA studies. Due to a wide range of effort levels in the collection of conventional parameters among these studies, only Ammonia, Orthophosphate, Total Phosphorus, and Total Suspended Solids were used for this analysis.
Despite this shortcoming, these parameters represent an effective suite of water quality indicators. These parameters are summarized by study in their MDS configurations in Figure 4(a). Bottom water chemistry was not markedly different among the majority of the tidal streams, save for Texas City Pump Canal and the Mission River. All other streams clustered in a relatively small area within the chemical constituent-based MDS. The ANOSIM procedure revealed a significant difference among the studies (Global $R=0.389$, $P<0.001$ ), with the present Mission-Aransas study being the most unique in terms of surface water chemistry. As was the case with the physical properties, the overall influence of the increased salinities on the Mission River (as recorded by 
TABLE 2: Field parameters by tidal stream. Color coding of studies follows Figure 1. Temperature (Temp.) in ${ }^{\circ} \mathrm{C}$, Dissolved Oxygen (D.O.) in $\mathrm{mg} / \mathrm{L}$, Specific Conductance (Specific Cond.) in $\mu \mathrm{mhos} / \mathrm{cm}$, Salinity in PSU, Secchi depth in $\mathrm{m}$. Data are means, standard deviations in parenthesis. See text for individual stream sample sizes. Dashed lines (-) indicate parameter not measured.

\begin{tabular}{|c|c|c|c|c|c|c|c|c|c|c|c|c|}
\hline Tidal stream & Temp. & (SD) & $\mathrm{pH}$ & (SD) & D.O. & (SD) & Specific conduct. & (SD) & Salinity & $(\mathrm{SD})$ & Secchi depth & (SD) \\
\hline$\Delta$ Mission & 30.97 & $(0.6)$ & 8.19 & $(0.2)$ & 5.70 & $(0.9)$ & 37095.83 & $(20748.3)$ & 23.96 & $(14.5)$ & 0.58 & $(0.1)$ \\
\hline$\triangle$ Aransas & 31.54 & $(0.6)$ & 8.54 & $(0.2)$ & 7.27 & $(0.8)$ & 17409.17 & $(15531.3)$ & 10.63 & $(9.9)$ & 0.41 & $(0.2)$ \\
\hline Nueces & 29.83 & $(1.0)$ & 8.25 & $(0.3)$ & 7.30 & $(3.1)$ & 12350.00 & $(9810.1)$ & 6.62 & $(5.5)$ & 0.35 & $(0.1)$ \\
\hline Mission & 31.13 & $(1.1)$ & 7.90 & $(0.1)$ & 7.27 & $(1.3)$ & 13051.67 & $(10486.9)$ & 6.73 & $(5.6)$ & 0.55 & $(0.1)$ \\
\hline Aransas & 31.18 & $(1.3)$ & 8.20 & $(0.2)$ & 9.02 & $(2.1)$ & 22716.67 & $(8694.9)$ & 12.15 & $(5.0)$ & 0.40 & $(0.1)$ \\
\hline Bastrop & 29.22 & $(1.5)$ & 7.72 & $(0.3)$ & 6.13 & $(1.6)$ & 18181.67 & (18138.4) & 10.32 & $(11.0)$ & 0.52 & $(0.2)$ \\
\hline Chocolate & 29.85 & $(1.5)$ & 7.80 & $(0.2)$ & 7.47 & $(1.9)$ & 11792.67 & $(10805.3)$ & 6.20 & $(5.9)$ & 0.48 & $(0.1)$ \\
\hline \multicolumn{13}{|l|}{$\nabla$ Nueces } \\
\hline$\checkmark$ Armand & 29.41 & $(1.5)$ & 8.12 & $(0.6)$ & 6.16 & $(2.4)$ & 4411.56 & $(6059.0)$ & 2.50 & $(3.5)$ & 0.45 & $(0.2)$ \\
\hline$\diamond$ Halls & 29.80 & $(1.4)$ & 7.70 & $(0.4)$ & 5.74 & $(2.1)$ & 4810.50 & $(7080.5)$ & 2.76 & $(4.2)$ & 0.48 & $(0.3)$ \\
\hline$\checkmark$ Oyster & 26.91 & $(4.4)$ & 7.26 & $(0.4)$ & 6.22 & $(1.3)$ & 6036.46 & $(7647.2)$ & 3.47 & $(4.6)$ & 0.27 & $(0.1)$ \\
\hline$\diamond$ Dickinson & 25.51 & $(4.7)$ & 7.80 & $(0.3)$ & 6.78 & $(1.6)$ & 7443.64 & $(7920.6)$ & 4.30 & $(4.8)$ & 0.37 & $(0.2)$ \\
\hline$\diamond \mathrm{TCPC}$ & 24.14 & $(4.0)$ & 7.84 & $(0.4)$ & 7.17 & (3.5) & 12570.91 & $(7247.8)$ & 7.35 & $(4.4)$ & 0.33 & $(0.1)$ \\
\hline$\diamond \mathrm{HBDC}$ & 26.06 & (5.4) & 8.03 & $(0.4)$ & 6.57 & (1.9) & 24300.00 & $(13670.7)$ & 14.81 & $(8.7)$ & 0.52 & $(0.1)$ \\
\hline$\checkmark$ Cedar Lake & 24.65 & $(3.5)$ & 7.71 & $(0.3)$ & 5.39 & $(1.1)$ & 10979.36 & $(15294.5)$ & 6.65 & $(9.5)$ & 0.33 & $(0.1)$ \\
\hline - Tres Palacios & 25.60 & $(4.3)$ & 7.70 & $(0.6)$ & 6.75 & $(1.5)$ & 5410.97 & $(6439.5)$ & 3.08 & $(3.8)$ & 0.30 & $(0.2)$ \\
\hline - Carancahua & 25.83 & $(4.5)$ & 7.71 & $(0.6)$ & 6.18 & $(1.7)$ & 4080.94 & $(5405.5)$ & 2.29 & $(3.2)$ & 0.24 & $(0.1)$ \\
\hline - Garcitas & 28.16 & $(5.1)$ & 7.52 & $(0.5)$ & 6.04 & $(1.2)$ & 2522.25 & $(4758.4)$ & 1.42 & $(2.8)$ & 0.26 & $(0.2)$ \\
\hline - Cow Bayou & 25.52 & $(5.0)$ & 6.57 & $(0.5)$ & 5.05 & $(1.6)$ & 1953.46 & $(3397.3)$ & 1.08 & $(1.9)$ & 0.48 & $(0.2)$ \\
\hline - Lost River & 26.14 & $(4.2)$ & 7.67 & $(0.3)$ & 7.27 & $(1.5)$ & 628.36 & $(892.2)$ & 0.34 & $(0.6)$ & 0.36 & $(0.1)$ \\
\hline - Arroyo Colorado & 30.83 & $(0.8)$ & - & - & 16.73 & $(3.2)$ & - & - & 14.67 & $(8.1)$ & - & - \\
\hline - Rio Grande & 30.00 & $(1.0)$ & - & - & 13.70 & $(4.3)$ & 一 & 一 & 10.17 & $(10.1)$ & - & - \\
\hline - Arroyo Colorado & 30.74 & $(1.6)$ & - & - & 7.46 & $(1.6)$ & - & - & 4.59 & $(8.1)$ & - & - \\
\hline - Rio Grande & 31.55 & $(4.7)$ & - & - & 7.92 & $(4.7)$ & - & - & 12.63 & $(6.6)$ & - & - \\
\hline
\end{tabular}

TABLE 3: Conventional parameters by tidal stream. Color coding of studies follows Figure 1. Ammonia, Orthophosphate (Orthophos.), Total Phosphorus (Total Phos.), Total Suspended Solids (TSS), and Total Organic Carbon (TOC) in mg/L. Chlorophyll a (Chl_a) in $\mu \mathrm{g} / \mathrm{L}$. Data are means, standard deviations in parenthesis. See text for individual stream sample sizes. Dashed lines $(-)$ indicate parameter not measured.

\begin{tabular}{|c|c|c|c|c|c|c|c|c|c|c|c|c|}
\hline Tidal stream & Ammonia & (SD) & Orthophos. & $(\mathrm{SD})$ & Total Phos. & $(\mathrm{SD})$ & $\mathrm{Chl} \mathrm{a}$ & (SD) & TSS & (SD) & TOC & (SD) \\
\hline$\Delta$ Mission $^{1}$ & 0.04 & $(0.06)$ & 0.02 & $(0.01)$ & 0.14 & $(0.07)$ & - & - & 43.51 & $(35.04)$ & - & - \\
\hline$\Delta$ Aransas $^{1}$ & 0.04 & $(0.03)$ & 0.20 & $(0.21)$ & 0.49 & $(0.18)$ & - & - & 44.68 & $(22.65)$ & - & - \\
\hline Armand & 0.07 & $(0.04)$ & 0.26 & $(0.15)$ & 0.39 & $(0.22)$ & 34.92 & $(41.61)$ & 38.33 & $(22.36)$ & 6.87 & (1.13) \\
\hline$\diamond$ Halls & 0.07 & $(0.02)$ & 0.11 & $(0.05)$ & 0.17 & $(0.06)$ & 14.54 & $(8.50)$ & 28.06 & $(18.27)$ & 8.53 & $(2.55)$ \\
\hline$>$ Oyster & 0.08 & $(0.06)$ & 0.12 & $(0.12)$ & 0.22 & $(0.26)$ & 13.67 & $(14.80)$ & 54.74 & $(51.00)$ & 11.94 & $(7.71)$ \\
\hline$\diamond$ Dickinson & 0.43 & $(0.84)$ & 0.16 & $(0.06)$ & 0.22 & $(0.07)$ & 17.59 & $(12.92)$ & 25.95 & (16.03) & 7.57 & $(6.66)$ \\
\hline$\checkmark \mathrm{TCPC}$ & 0.24 & $(0.53)$ & 0.09 & $(0.04)$ & 0.16 & $(0.06)$ & 22.47 & (19.97) & 17.33 & $(4.80)$ & 1.78 & $(3.83)$ \\
\hline$\diamond \mathrm{HBDC}$ & 1.83 & $(1.94)$ & 2.10 & $(2.26)$ & 3.16 & $(3.44)$ & 108.48 & $(59.18)$ & 37.00 & (19.35) & 4.46 & $(7.34)$ \\
\hline$\checkmark$ Cedar Lake & 0.03 & $(0.01)$ & 0.09 & $(0.04)$ & 0.15 & $(0.03)$ & 7.17 & $(5.08)$ & 22.25 & $(11.22)$ & 9.08 & $(6.44)$ \\
\hline - Tres Palacios & 0.07 & $(0.04)$ & 0.20 & $(0.17)$ & 0.28 & $(0.18)$ & 15.68 & $(19.60)$ & 127.94 & $(221.79)$ & 6.20 & $(1.57)$ \\
\hline - Carancahua & 0.06 & $(0.02)$ & 0.20 & $(0.11)$ & 0.29 & $(0.17)$ & 13.77 & (18.29) & 42.97 & $(31.63)$ & 7.77 & $(1.54)$ \\
\hline - Garcitas & 0.07 & $(0.03)$ & 0.14 & $(0.10)$ & 0.19 & $(0.08)$ & 9.37 & (10.79) & 38.53 & $(60.73)$ & 10.31 & $(4.37)$ \\
\hline - Cow Bayou & 0.07 & $(0.04)$ & 0.09 & $(0.08)$ & 0.10 & $(0.05)$ & 8.48 & $(10.67)$ & 15.63 & (11.95) & 11.25 & (4.18) \\
\hline - Lost River & 0.05 & $(0.01)$ & 0.07 & $(0.02)$ & 0.14 & $(0.04)$ & 11.67 & $(10.87)$ & 35.77 & $(16.72)$ & 6.37 & $(0.55)$ \\
\hline
\end{tabular}

${ }^{1}$ Chlorophyll a readings were not collected from the Mission and Aransas Rivers because water chemistry analysis was done on bottom-water samples. 


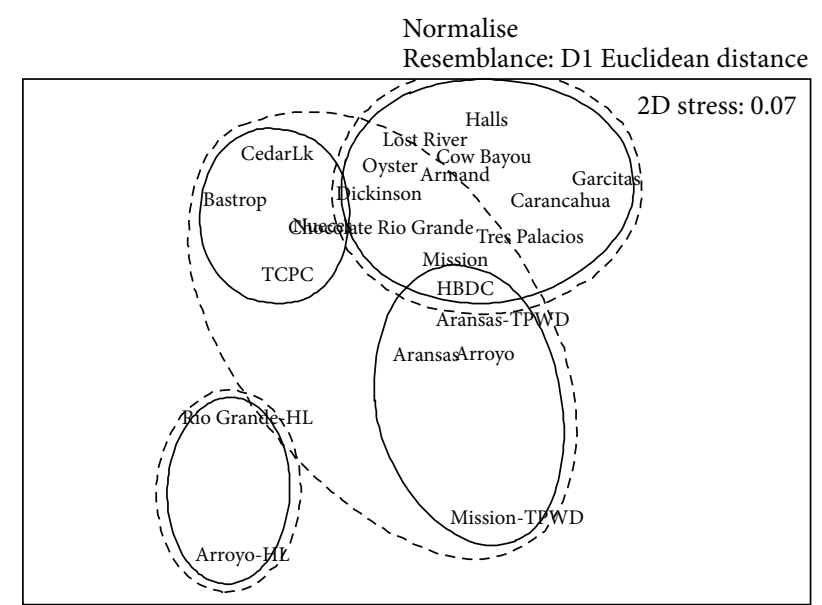

Distance
-3
---4

FIGURE 3: Multidimensional scaling ordination means plot of the tidal streams based on surface measurements of field parameters. Streams within a common ellipse are not significantly different at the $\alpha=0.1$ level (dashed line) and the $\alpha=0.05$ level (solid line). Distance based on Euclidean distances of pairwise similarity measures taken from a complete linkage Cluster Analysis of the complete similarity matrix (not shown).

Total Suspended Solids) was most influential in separating out specific tidal streams (Figure 4(b)). Nutrient loadings, as measured by Ammonia and Orthophosphate concentrations, showed that the high nutrient levels encountered in the Aransas River were generally similar to the elevated concentrations of both of these constituents encountered in the Texas City Pump Canal and the Highland Bayou Diversion Canal (TCEQ Studies, see Figures 5(a) and 5(b)).

\subsection{Nekton Communities}

3.3.1. Nearshore Seine Collections. The MDS configuration of the summer season seine collections from each study is shown in Figure 6(a). Similar to the MDS configuration of the Physical properties, this community-based analysis again showed a degree of overlap among the geographic locations of the studies, with the underlying salinity gradient differences also evident in the biotic collections (Figure 6(b)). The $R$ values of the ANOSIM test confirmed statistical differences, with $R$ statistics ranging from a low of 0.361 comparing the WQS collections to the TPWD Studies on the Lower Coast, to a high of $R=0.881$ when comparing the MA collections to the Harper and Landry work on the Lower Coast. Despite the underlying salinity differences, very similar nekton communities were found within each tidal stream. Only a relatively few number of taxa comprised the vast majority of individuals, with bay anchovy Anchoa mitchilli, grass shrimp Palaemonetes spp., Gulf menhaden Brevoortia patronus, brown shrimp Farfantepenaeus aztecus, white shrimp Litopenaeus setiferus, and silversides (a mixture of Menidia spp. and Membras martinica) dominating the catches from nearly every location (Table 4 ). While the relative proportions of these taxa changed in response to the salinity conditions encountered, each consistently made up the majority of the biota collected with the seines.

Taxonomic diversity and distinctness tests can be used to account for any systematic biases among the different studies, because one of the qualities of these diversity measures is that they are sample-size independent. This fact can be exploited when comparing current data to historical datasets, or more importantly for the present study, for comparing different studies for which the sampling effort is unequal or uncontrolled. Using the species lists from the six different studies under consideration as the master list, a total of 179 unique taxa have been encountered in tidally influenced systems along the Texas coast. The taxonomic groupings used for the master species list were species, genus, family, order, class, and phyla, with equal step lengths between adjacent taxonomic levels of 16.67 (species within different phyla therefore would be at a taxonomic distance of $\omega=100$ ). Figure 7(a) displays the funnel plot for the seine collections, catering for all sublist sizes up to 150 species. The simulated 95\% probability limits, based on 999 random selections for each sublist size up to 150 , is also shown. Mean taxonomic distinctness is relatively constant at sample diversities greater than 35 taxa, and this diversity level equates to class and order level differences. The limits become increasingly wide as sample diversity decreases, reducing the likelihood of being able to detect a change in distinctness in species-poor collections.

From Figure 7(a), systematic biases among the studies uncovered in the MDS configurations are still evident, as the more uniform sampling strategies used for the MissionAransas study and the original UAA work tended to produce clusters of stations more closely together. The lowest degree of taxonomic diversity was recorded in the WQS study, although the only sampling stream to have a mean taxonomic diversity value outside the $95 \%$ probability limit were collections on Oyster Bayou from the TCEQ studies. Seine collections from the most recent efforts on the Mission and Aransas Rivers were generally near the theoretical mean, with overall diversity slightly higher within the Mission River. In terms of variation of taxonomic diversity, Mission River was significantly higher than expected (Figure 7(b)), and this may be a reflection of the dramatically higher salinity conditions that were encountered on this tidal segment. Recalling from Figure 4(b), salinities on the Mission River were the most variable, going from nearly fresh to hypersaline. This high degree of taxonomic variability is the result of the dominance by bay anchovy abundance relative to the remainder of the taxa collected with this gear.

3.3.2. Midchannel Trawl Collections. The MDS configuration of the otter trawl collections is presented in Figure 8(a). The nekton communities recorded by this gear also confirmed the underlying biases of the different sampling protocols, as Figure 8(b) is essentially divided between the UAA and MA collections on the right half of the graph, and all other 

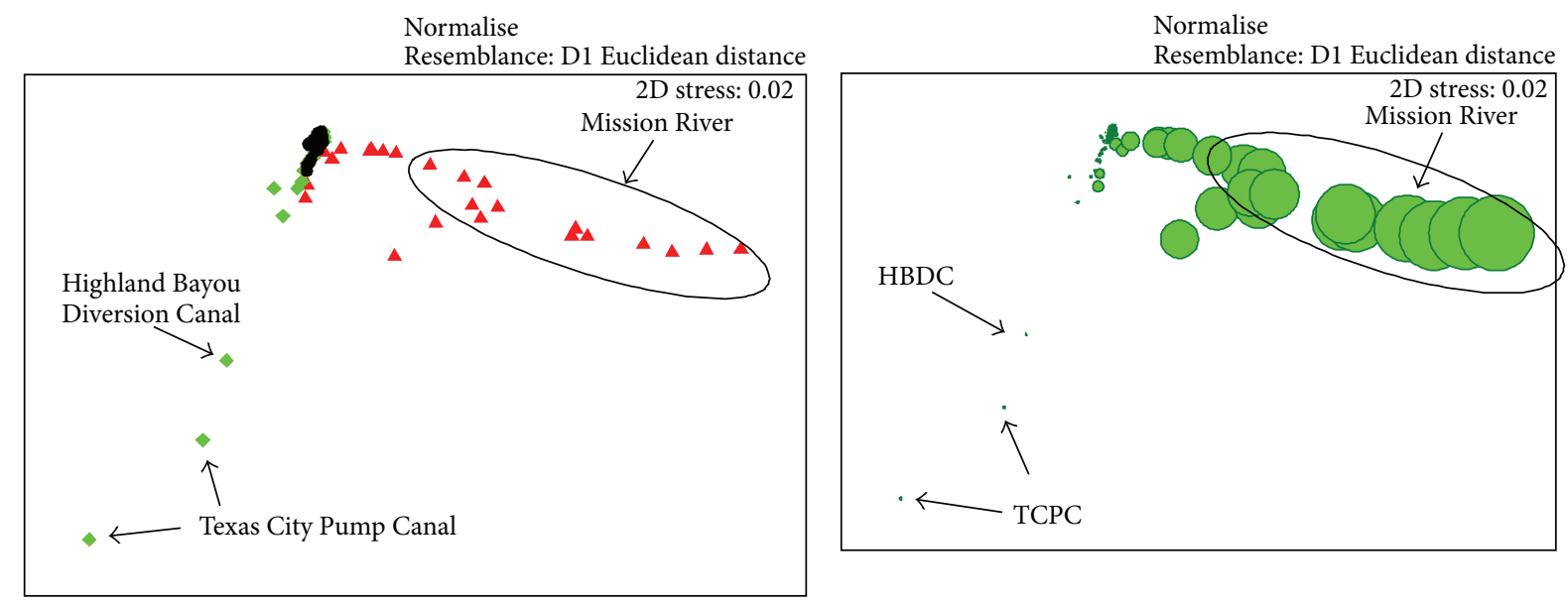

Study

$\triangle \mathrm{MA}$

TSS $(\mathrm{mg} / \mathrm{L})$

$5 E 3$

$\checkmark$ TCEQ

$2 E 4$

$3.5 E 4$

- UAA

$5 E 4$

(a)

(b)

FIGURE 4: MDS configuration of the stations based on bottom-water collections of conventional parameters from all studies. (a) Stations within studies configuration (streams discussed in the text individually labeled); (b) overlaid with surface-water column Total Suspended Solids concentration. Size of each circle is represented by the scale in the keys.
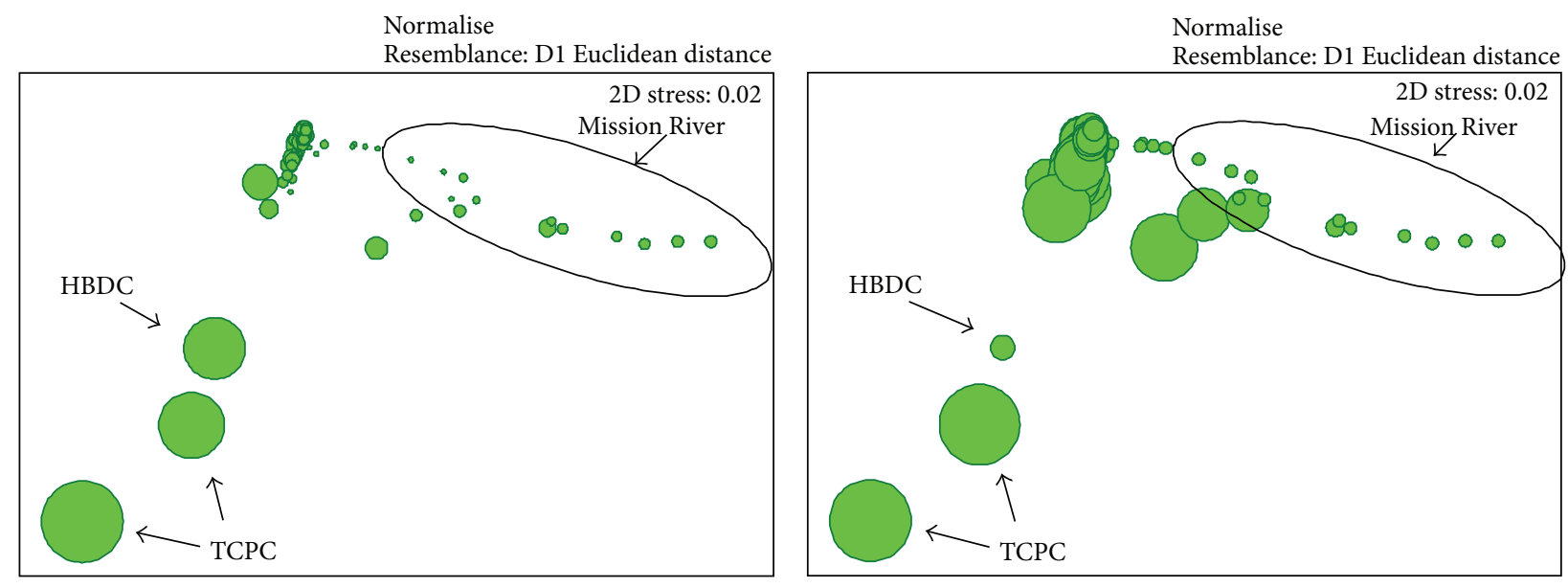

Ammonia (mg/L)

Orthophos (mg/L)
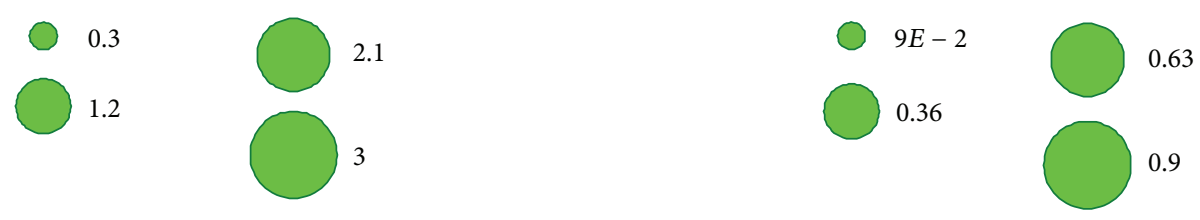

(a)

(b)

FIGURE 5: MDS configuration of the stations based on Figure 4(a), overlaid with (a), Ammonia concentrations; and (b), Orthophosphate concentrations of bottom waters from all studies. Size of each circle is represented by the scale in the keys. 
TABLE 4: Relative contribution of each taxa (\% of total, by study) to at least $95 \%$ of the overall community structure as measured by shallow water seines during the summer season. Dashed lines represent contributions of $\ll 1.0 \%$; empty cells represent taxa not encountered during summer sampling.

\begin{tabular}{|c|c|c|c|c|c|c|}
\hline Taxa & MA & WQS & TCEQ & UAA & LCS-HL & LCS-TPWD \\
\hline Bay anchovy & 30.44 & 52.48 & 15.41 & 3.39 & 65.83 & 3.29 \\
\hline Grass shrimp & 14.50 & 5.40 & 42.87 & 1.08 & 1.26 & 3.47 \\
\hline Gulf menhaden & 14.28 & 16.06 & 3.16 & 89.98 & - & 4.50 \\
\hline Tidewater silverside & 13.55 & & 0.98 & 0.16 & - & 4.46 \\
\hline Brown shrimp & 4.93 & & 0.50 & 0.83 & 2.73 & 6.05 \\
\hline White shrimp & 3.51 & 19.22 & 10.93 & 1.18 & 3.13 & 14.98 \\
\hline Sheepshead minnow & 3.48 & - & 3.82 & - & - & 2.70 \\
\hline Gulf killifish & 2.23 & - & 0.67 & - & & 1.68 \\
\hline Sailfin molly & 2.12 & 0.61 & 2.86 & 0.25 & & \\
\hline Gulf pipefish & 1.67 & & - & - & - & \\
\hline Naked goby & 1.36 & - & - & - & - & - \\
\hline Striped mullet & 1.24 & - & - & 0.21 & - & 6.36 \\
\hline Rio Grande cichlid & 1.13 & & & & & \\
\hline Western mosquitofish & 1.05 & 0.43 & 6.38 & 0.90 & & - \\
\hline Blue crab & - & - & 2.25 & 0.32 & 1.03 & 1.76 \\
\hline Inland silverside & - & 2.80 & 3.37 & - & 5.01 & 2.23 \\
\hline Spotted seatrout & - & 0.53 & - & - & & \\
\hline Spot & & 0.22 & - & - & - & 2.96 \\
\hline Spotted sunfish & & - & 3.62 & - & & \\
\hline Scaled sardine & & & - & & 9.39 & - \\
\hline Mojarra sp. & - & - & - & - & 5.11 & 1.08 \\
\hline Striped anchovy & & - & - & & 2.24 & - \\
\hline Darter goby & & & - & - & 1.30 & \\
\hline Finescale menhaden & & & & & & 17.23 \\
\hline White mullet & & - & - & - & - & 7.38 \\
\hline Hardhead catfish & - & - & - & & - & 5.97 \\
\hline Pinfish & - & - & - & - & - & 4.84 \\
\hline Crevalle jack & & - & - & & & 2.04 \\
\hline Highfin goby & & & & & & 1.31 \\
\hline Lesser blue crab & & & & & & 1.16 \\
\hline Sum-\%total & 95.48 & 97.75 & 96.82 & 98.31 & 97.03 & 95.44 \\
\hline
\end{tabular}

collections on the left half of the graph. Unlike the MDS configuration of the seines, the community-based analysis of the otter trawls showed that salinity was generally less important in structuring the nekton communities across studies. Within a common collection of streams, the same communities were found across widely differing salinity gradients (i.e., Cedar Lakes, Oyster Bayou, and Lost River are statistically similar over an order of magnitude difference in mean salinity, see Figure 8(b)). Standardizing the differences in total catch numbers of individuals by their relative percentages (Table 5), the total numbers of taxa encountered in each study was generally similar Most of the studies encountered between 16 and 23 unique taxa with the otter trawls, although the Lower Coast Studies by TPWD encountered a total of 34 taxa. Many of the taxa exclusive to the lower coast that led to the significant differences amongst the assemblages (ranging from a low of $R=0.456, P<0.001$, LC-TWPD compared to TCEQ, to a high of $R=0.95, P<0.001$, LC-HL compared to the MA work) were the more tropical species indicative of the biogeographical shift from temperate to the tropical fauna of the southern Gulf of Mexico (e.g., lesser blue crab Callinectes similis, common snook Centropomus undecimalis, shoal flounder Syacium gunteri, and jack crevalle Caranx hippos; see Table 5). Nekton communities from each study were dominated by only a few taxa, with only ten taxa defining the otter trawl collections regardless of location or underlying salinity gradient. Those included bay anchovy, Gulf menhaden, blue catfish Ictalurus furcatus, white shrimp, Atlantic croaker Micropogonias undulatus, sand seatrout Cynoscion arenarius, brown shrimp, striped mullet Mugil cephalus, spot Leiostomus xanthurus, and blue crab Callinectes sapidus. The assemblages of these ten taxa accounted for between $63.2 \%$ and $99.2 \%$ of all individuals encountered in each study.

Average taxonomic diversity was markedly lower on the Mission River in the MA study, when compared to previous 

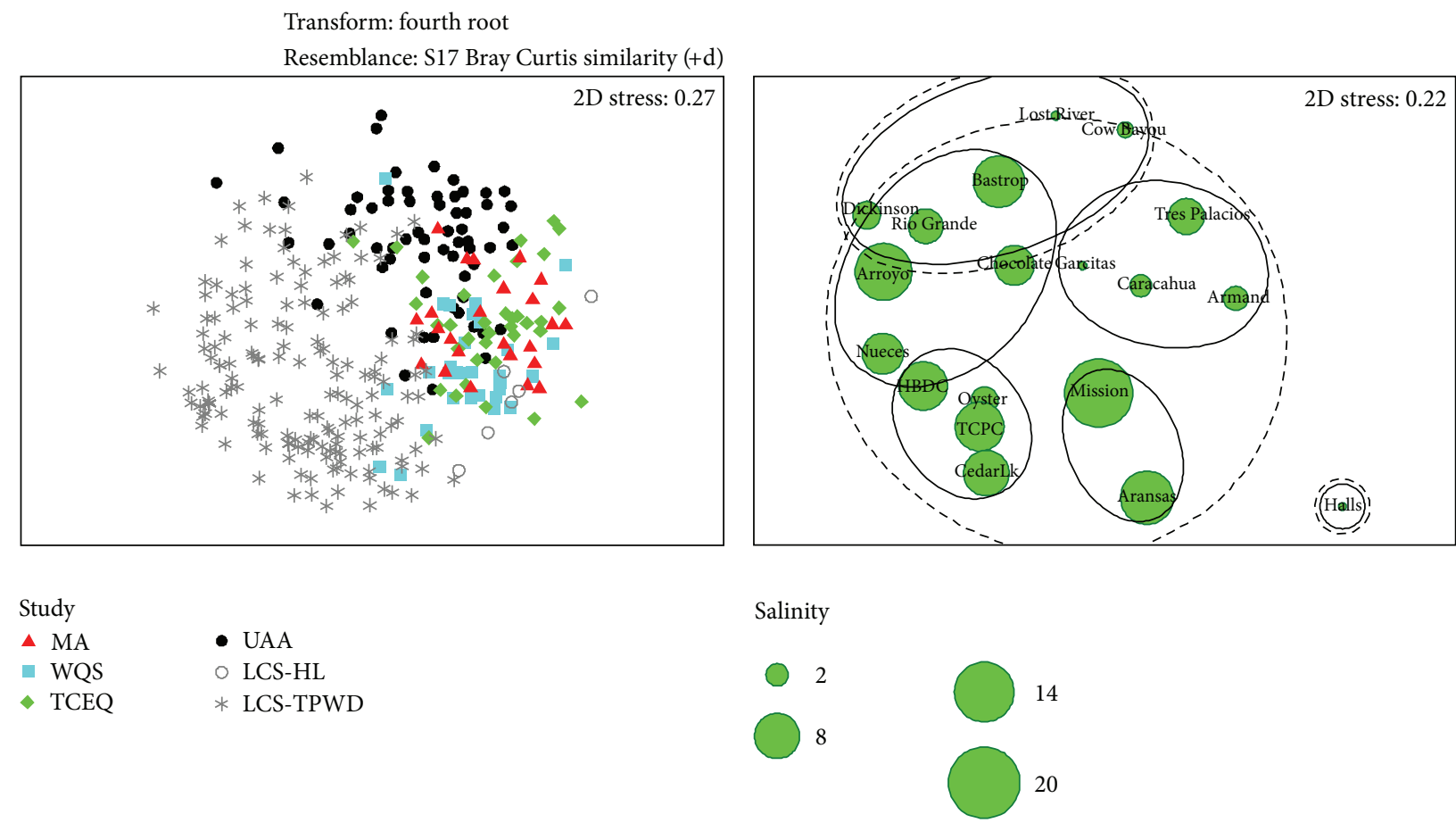

(a)

(b)

FIGURE 6: MDS configuration of the stations based on summer season nekton communities collected with seines; (a) color coded by study; and (b) MDS means plot by river, overlaid with mean salinities (size of each circle is represented by the scale in the keys). Significance determinations follow the $\alpha$ value and Bray Curtis distance measure outlined in Figure 3.
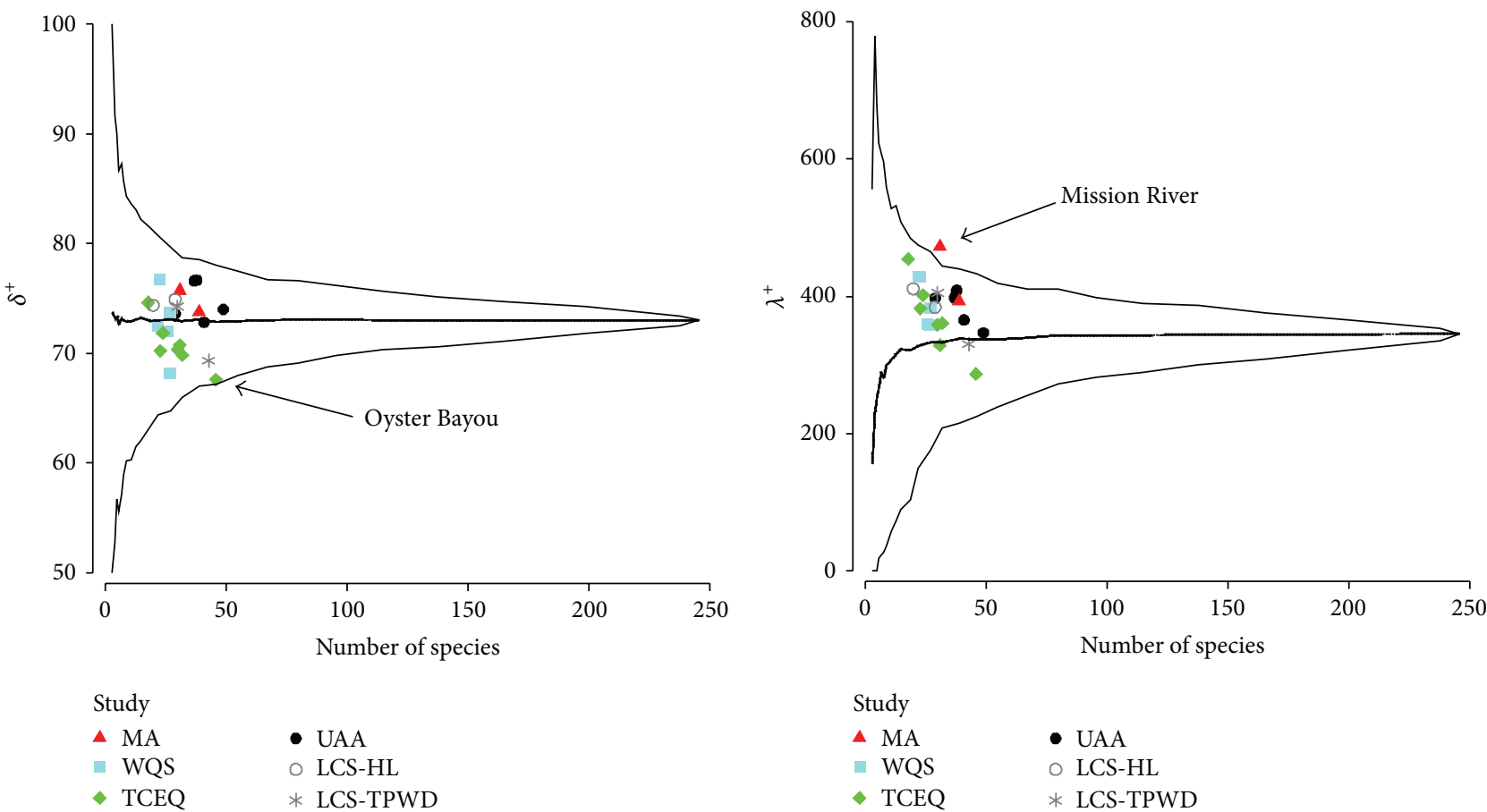

(a)

(b)

FIgURE 7: Funnel plot for simulated Average Taxonomic Distinctness (a) and Variation in Taxonomic Distinctness (b) of seine collections, from 999 sublists drawn randomly from a master species list of 179 taxa. Upper and lower control lines represent the $95 \%$ probability limits of the simulated values; thin line indicates theoretical mean. Points are color coded by study and represent the mean diversity values of seine collections at each location. 
TABLE 5: Relative contribution of each taxa (\% of total, by study) to at least $95 \%$ of the overall community structure as measured by midchannel otter trawls during the summer season. Dashed lines represent contributions of $\ll 1.0 \%$; empty cells represent taxa not encountered during summer sampling.

\begin{tabular}{|c|c|c|c|c|c|c|c|}
\hline Taxa & MA & WQS & NTS & TCEQ & UAA & LC-HL & LC-TPWD \\
\hline Bay anchovy & 92.82 & 10.63 & 2.18 & 10.25 & 56.69 & 2.23 & 1.44 \\
\hline Gulf menhaden & 3.71 & - & 15.05 & 0.94 & 33.04 & - & 6.78 \\
\hline Blue catfish & 1.91 & - & 18.02 & 3.59 & 2.54 & & - \\
\hline White shrimp & - & 81.29 & 18.26 & 53.89 & 2.57 & 11.72 & 22.46 \\
\hline Atlantic croaker & - & 3.42 & 9.65 & 6.90 & - & 7.72 & 12.30 \\
\hline Sand seatrout & - & 1.63 & 1.08 & 8.99 & 0.96 & 2.23 & 1.16 \\
\hline Brown shrimp & - & - & 17.24 & 3.98 & 0.70 & 11.28 & 1.63 \\
\hline Striped mullet & - & - & 4.45 & - & - & - & 3.63 \\
\hline Hardhead catfish & - & - & 3.62 & - & - & 2.23 & 2.77 \\
\hline Spot & - & - & 1.71 & 4.21 & - & 23.29 & 9.50 \\
\hline Blue crab & - & - & 1.31 & 3.57 & - & 4.75 & 8.62 \\
\hline Gizzard shad & - & - & 1.28 & - & - & & - \\
\hline Silver perch & - & - & 0.97 & - & - & 5.93 & 2.03 \\
\hline Pinfish & & - & 0.55 & - & & 0.89 & 10.42 \\
\hline Silver seatrout & & & & & & 6.68 & - \\
\hline Atlantic cutlassfish & & & & & & 2.97 & - \\
\hline Scaled sardine & & & & & & 2.97 & - \\
\hline Family Macrobrachium & - & & - & - & - & 2.97 & \\
\hline Bay whiff & & - & - & - & - & 2.52 & 1.05 \\
\hline Striped anchovy & & & & - & & 2.52 & - \\
\hline Mojarra species & & & & - & & 1.19 & 2.03 \\
\hline Atlantic moonfish & & & & & & 0.74 & - \\
\hline Gafftopsail catfish & & - & - & - & - & 0.74 & - \\
\hline Grass shrimp & & & - & - & - & & 2.20 \\
\hline Red drum & & & - & & - & & 1.19 \\
\hline Lesser blue crab & & & & & & & 1.15 \\
\hline Common snook & & & & & & & 0.99 \\
\hline Shoal flounder & & & & & & & 0.69 \\
\hline Channel catfish & - & - & & & - & & 0.68 \\
\hline Threadfin shad & - & & - & - & - & & 0.65 \\
\hline Gafftopsail catfish & & - & - & - & - & - & 0.45 \\
\hline Atlantic threadfin & & & & & & - & 0.44 \\
\hline Bigmouth sleeper & & & & & & & 0.42 \\
\hline Fringed flounder & & & & & & & 0.34 \\
\hline Crevalle jack & & & & & & & 0.32 \\
\hline Sum-\%total & 98.44 & 96.97 & 95.37 & 96.32 & 96.5 & 95.57 & 95.34 \\
\hline
\end{tabular}

works (Figure 9(a)), although this level was still within the $95 \%$ confidence limits of the theoretical mean for that given number of species. This lower degree of diversity from the Mission River is a reflection of the hypersaline conditions that the persistent drought brought to this system, where bay anchovy vastly outnumbered all other taxa during the summer sampling periods (Table 5). Only Chocolate Bayou, part of the WQS studies on the middle and upper coast, had mean diversities far greater than expected values for a given sample size. These collections had the lowest within-group average similarity values (SIMPER average similarity value = 1.8 ; see [12]), even though the vast majority of the individuals were still part of the ten most dominant taxa found coastwide (from Chocolate Bayou; white shrimp, bay anchovy, and sand seatrout). In each study, variation in taxonomic diversity was above the expected theoretical mean (Figure 9(b)), and this is a direct reflection of each collection being dominated by only a few taxa, in some cases greatly outnumbering all others, when community structure was measured by the otter trawls. Generally missing from the configurations of taxonomic diversity was a connection between degraded water bodies (e.g., Highland Bayou Diversion Canal, Texas City Pump Canal; see Figures 5(a) and 5(b)) and a general lowering of observed diversity. The same suite of numerically 

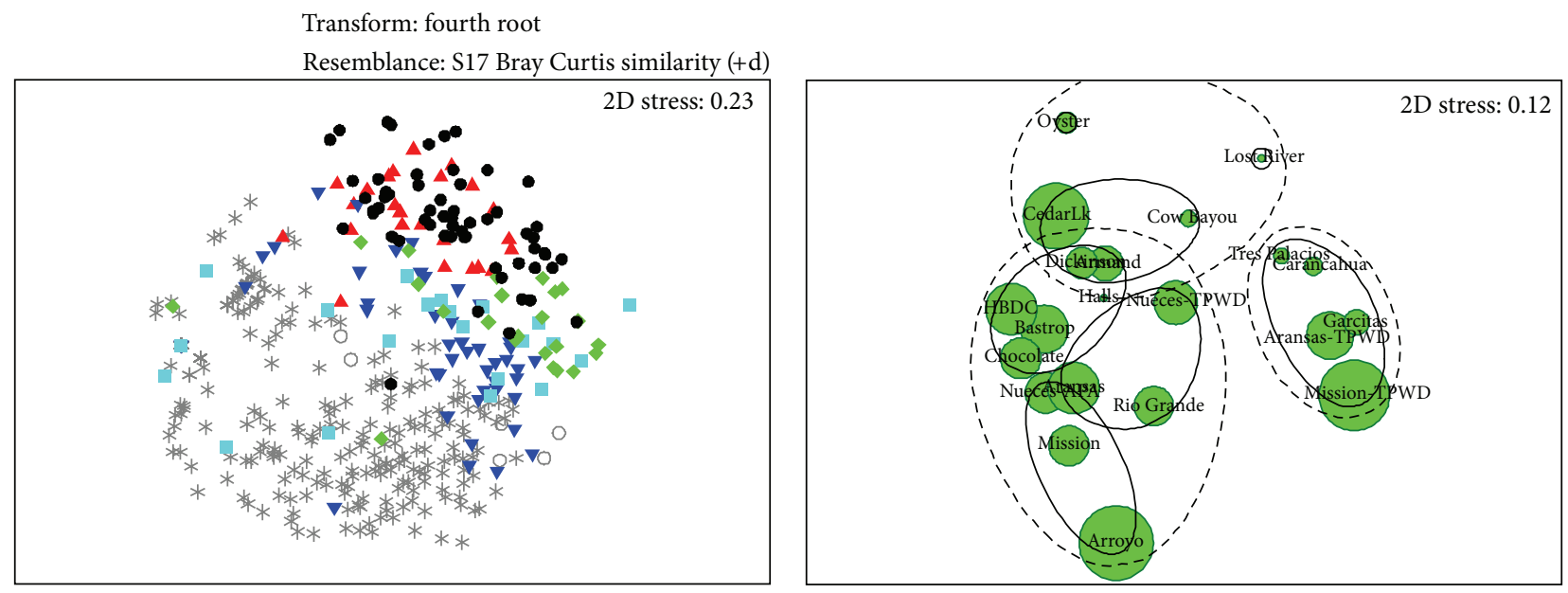

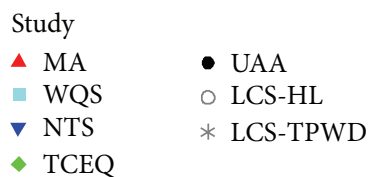

(a)

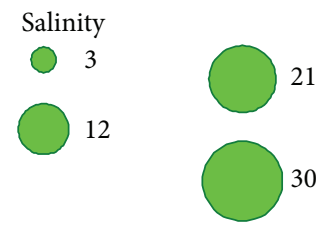

(b)

FIGURE 8: MDS configuration of the stations based on summer season nekton communities collected with otter trawls; (a) color coded by study; and (b) MDS means plot by river, overlaid with mean salinities (size of each circle is represented by the scale in the keys). Significance determinations follow the $\alpha$ value and Euclidean distance measure outlined in Figure 3.

dominant taxa appears to be ubiquitous along the entire Texas coast.

\section{Discussion}

Assessing the factors which influence the diversity of taxa and their associated abundance levels within an assemblage has long been a common theme in studies of community ecology [18-21]. These assessments are most robust when the effect of sampling scales on the observed community structure patterns are taken into account $[22,23]$. While the topic of scale has received explicit attention in some freshwater [24-26] and marine fish studies [1, 27, 28], studies on fish communities within estuaries, especially those residing in the tidally influenced portions of the estuary, less often deal explicitly with this issue of scale (although see Bacheler et al. [11, 20] for more recent examples of estuarine studies addressing the confounding effects of scale). Many factors have been proposed as the driver responsible for determining estuarine nekton assemblage structure and these occur at vastly different scales and in a variety of ways: from the global scale at which species richness and abundance may be strongly influenced by latitudinal gradients, estuary size, habitat diversity, and estuarine mouth configuration [11, 29, 30 ], to a more regional scale where factors such as salinity, temperature (e.g., seasonality), habitat type, or river flow may have a more pronounced impact on distribution and abundance $[3,9,31,32]$.
The initial task of the UAA studies, where the multivariate, community-based assessment methodology was first employed, was to identify which environmental drivers (or differences in the physical, chemical, or biological components of ecosystem health) could be shown to differentiate reference streams and "impacted" streams at disparate locations along the Texas coast. While these studies were limited both in their spatial and temporal scales, they initially served as the test-cases for the implementation of this assessment methodology. Based on those results, clear differences were generally lacking between streams classified as either Exceptional or High [16], and this lack of distinction between those designations cut across numerous levels of trophic structure. This seemingly negative result served to validate the assessment methodology as being internally coherent, at least at the local scale, because the same environmental driver that could be used to differentiate tidal streams locations (namely, salinity) was the common driver shaping community structure. The present study furthers this task of determining whether differences in the physical, chemical, or biological components of "ecosystem health" can be found among tidally influenced streams with varying degrees of freshwater inflows, because the issue of scale is now implicitly addressed. By comparing different suites of study locations spanning the length of the Texas coastline, and sampling efforts that spanned environmental conditions across multiple decades, the multivariate Assessment Methodology is robust enough to uncover community structure patterns at much larger scales. As previous authors have noted, there 


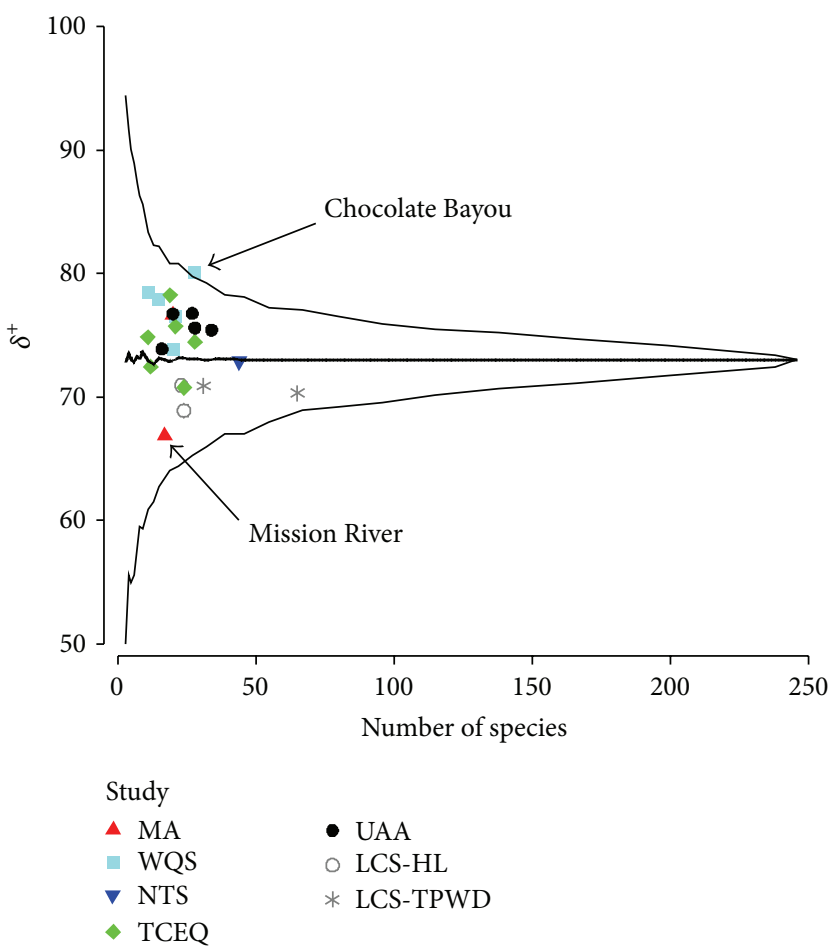

(a)

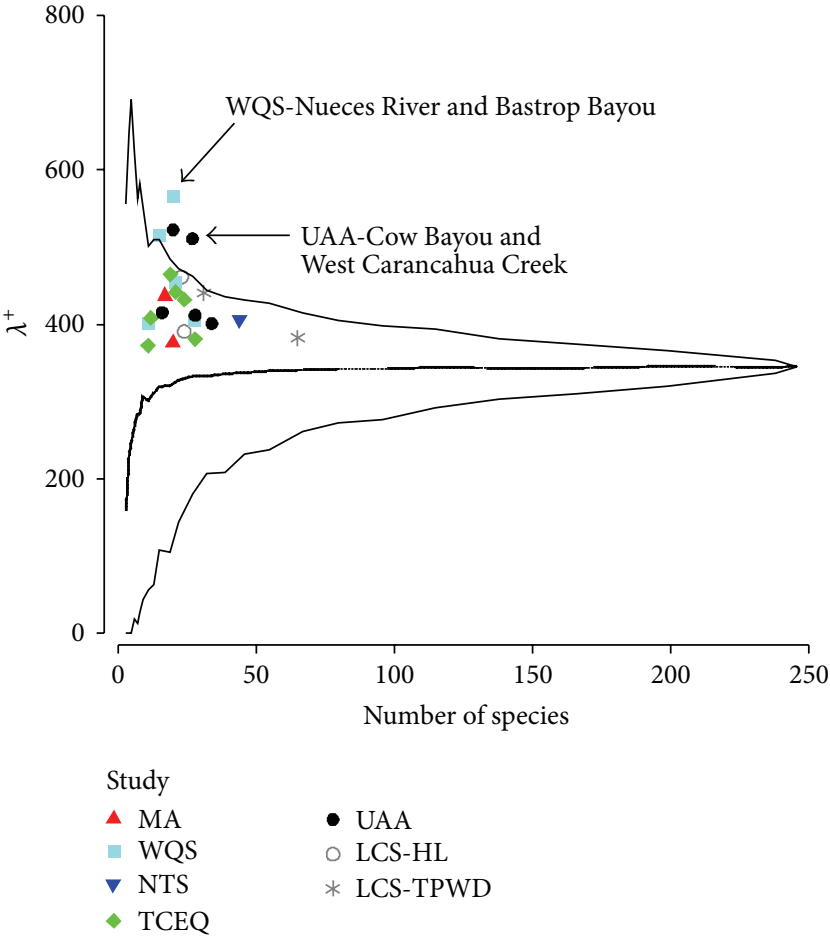

(b)

Figure 9: Funnel plot for simulated Average Taxonomic Distinctness (a) and Variation in Taxonomic Distinctness (b) of otter trawl collections, from 999 sublists drawn randomly from a master species list of 176 taxa. Upper and lower control lines represent the $95 \%$ probability limits of the simulated values; thin line indicates theoretical mean. Points are color coded by study and represent the mean Diversity values of trawl collections at each location.

is no single correct scale at which to quantify the spatial distribution of populations and some have suggested that habitat use must be examined on multiple scales $[22,23]$.

4.1. Water Quality Assessments. The ANOSIM tests within the Assessment Methodology revealed that there were significant differences among surface-water physical characteristics seen in the different studies (Figure 3), although the high degree of overlap among the individual streams discounted any large-scale latitudinal gradient along the coast. While pairwise comparisons revealed that the greatest degree of differences in surface water conditions was found between the lower coast and upper coast (Lower Coast Study by Harper and Landry compared to the UAA and TCEQ studies), these distinctions did not appear to be latitudinally consistent. As an example, the Mission-Aransas Study (MA) was statistically similar to all of the studies on the upper coast, even though the two rivers for this study are located geographically closer to the Nueces, Arroyo Colorado, and the Rio Grande than to any of the tidal streams on the upper Texas coast (see Figure 1). The important distinction within the ANOSIM tests of the physical characteristic was that when differences could be identified, the parameter most influential in separating out the groups of stations was universally salinity (Figure 2(b)). Taken at a larger spatial scale, a general gradient of lower salinities within the upper coast stations to higher salinities on the lower coast stations was evident, yet within a regional scale of an individual studies (WQS Study along the middle Texas coast) to a limited to local scale (TCEQ studies centered around Galveston Bay), this salinity trend is interrupted by the high degree of variability within different tidal segments (see Table 2). This overarching role of salinity (and secondarily, turbidity; see $[4,33]$ ) in structuring the available habitats within estuaries has been commonly reported $[11,21,34]$, and salinity was one of the most important factors identified by one of the largest-scale assessments of tidally influenced waters ever undertaken (European Union's Marine Strategy Directive; see [10]). The other physical parameters of temperature, dissolved oxygen concentrations, and $\mathrm{pH}$ readings were each far less influential in configuring the streams amongst the studies, although this could be attributed to the limiting temporal scale of the present study (only the common summer sampling season being the time period under consideration due to the nonuniformity of collections across studies).

The spatial and temporal coverage of water chemistry properties were far lower than those of the routine field parameters, and the general pattern of the study streams in the chemistry-based MDS space is markedly different (Figure 4(a)). Tidal streams generally considered as "impaired" were the systems that were identified by this analysis as being most unique. As an example, excess nutrient 
loads within Texas City Pump Canal and Highland Bayou Diversionary Canal lead to these systems generally falling outside the main MDS grouping. Mission River was also identified as being unique, but its location within the chemistrybased configuration was directly tied to the extreme salinities (as measured by the high TSS values) that were found in this system as a result of drought conditions during sampling. Again, the overarching role of salinity in defining measures of "ecological health" is again reinforced $[33,35]$.

4.2. Nekton Assemblages. Based on the nekton collections shown in Figure 6 (seine collections), salinity again appears to play at least some role in structuring community compositions. Yet, even across dramatic salinity differences, the same handful of taxa dominated the collections from every stream under consideration. The highly euryhaline families of Engraulidae, Penaeidae, Palaeomonidae, Atherinidae, Portunidae, and Clupeidae numerically dominated every stream, and these same families are common to all estuaries along the Gulf of Mexico and Atlantic coasts [36-40]. These families regularly exploit the wide variety of available habitats present within tidal systems, even across the climate-induced bias amongst the studies that was outlined by Tolan [12]. Missing from Figure 6 is a clear connection between any of the supposed "impaired" water quality streams to a subsequent "impaired” biological community. For example, communities recorded at Texas City Pump Canal were similar to those collected from the more pristine locations on the upper coast (Cedar Lake Creek, Oyster Bayou, and Lost River), as well as those from the middle and lower coast (Garcitas Creek and the Aransas River). Although sampling biases amongst the studies was quite evident (e.g., white shrimp, Atlantic croaker, and spot in the TCEQ studies; Gulf menhaden and bay anchovy in the UAA and MA studies), the same general nekton communities were recorded from each tidal system, regardless of any level of impairment.

Salinity appeared to have a lesser role in structuring the communities recorded with the otter trawls (Figure 8), and this could be a reflection of the different taxa recorded by this gear. While the dominance of the euryhaline families of Penaeidae, Engraulidae, and Clupeidae was still evident with the trawls, members of the families Sciaenidae (marine nekton) and Ictaluridae (freshwater nekton) made up the majority of the remainder of the catch with this gear. Both spot and Atlantic croaker (sciaenids) are noted for their abilities to inhabit brackish water conditions [41], and the blue catfish (ictalurid) is a freshwater species common in both fresh and brackish waters. Like the community structure seen with the seines, otter trawls did not appear to reflect any consistent connection of the "impaired" conditions, as revealed by the chemical constituents, and those seen with the biological components. The notion of scale is also relevant in addressing the MDS configurations of community composition, as it is thought that large-scale (kilometers) patterns in the distribution of organisms result primarily from species responses to their physical environment [42]. Abiotic factors may set up the community framework, while biotic interactions refine species distribution patterns within this structure. At the scale of the community, salinity appears to structure nekton diversity and abundance levels, whereas at the level of the individual (i.e., species), salinity does not have as large of an effect because of their physiological tolerances previously outlined. Given the extreme euryhaline/physiological abilities found in many of the species that comprise the biologic communities found within tidally influenced systems, few estuarine taxa earn a true description of "sensitive."

The application of this bioassessment, or more explicitly the derivation of a particular biocriteria metric with broad spatial applicability, expands upon the classical population ecology theory of stability and climax community structure, which was first introduced in the field of terrestrial ecology by Clements [43]. The general underlying assumption for this metric calculation is that communities can approach a condition of higher biological integrity when they are not impaired by disturbance, and in its implementation under the IBI approach, it implies that disturbance is linked with human activities [17]. However, tidal streams are not isolated systems with stable climax communities [44], and a number of studies indicate that the benthic macrofaunal communities of these areas are composed of metapopulations of colonizing generalists [45-47] and the fish community of these same areas is comprised of taxa that are ubiquitous to estuaries along the entire Gulf coast. The bioassessment approach thus breaks down, at least in terms of the present methodology as it has been applied to the nekton communities, precisely because the same groups of taxa always make up the "communities" no matter what environmental conditions are encountered. The only change in these communities is a change in their relative abundances under differing environmental conditions. For many of the taxa that define Texas tidal stream communities, abundance levels at the individual scale appear to be largely disconnected from the major environmental drivers that are currently used to describe "ecological conditions." The absence of any meaningful nekton-derived biocriterion "Index Score," especially one which could have broad spatial applicability, should not be viewed as a failure of the Assessment Methodology as a whole but rather a confirmation of the complexities in selecting indicators to be used in describing the condition of the ecosystem and its parts and subsets [48]. Clearly, the results of this study show that the nekton portions of tidally influenced ecosystems are not an especially sensitive indicator and that negative outcome does have broad spatial applicability. A successful Index Score development will thus have to be drawn from some other biological subset of the system.

Isolating the effects of the abiotic drivers on long-lived species, such as estuarine fishes, requires years of monitoring that span the range of natural conditions, and too often, data sufficient to detect the effects are not obtained until it is too late and the population has suffered measurable decline [18]. One approach in evaluating many fish-based metrics is to narrow the assessment time frame to some index period (usually during the "high stress summer period," see $[8,49]$ ). Intuitively, the inverse relationship between temperature and dissolved oxygen should be manifested as a large stressor on the monitored organisms, resulting in fewer species, 
fewer individuals, and lower biomass in areas of additional high anthropogenic stressors. Too much focus on a specific stressor alone can lead to misleading predictions of responses because of inadequate information on how other factors affect the response of the population [50]. In the present study, summer collections had a great degree of salinity-mediated variability in their community compositions, and would have required substantially more sampling effort to overcome their low statistical power. Expanding the temporal scale of the current analysis technique to more uniform datasets that encompass a greater seasonal resolution may lead to more illuminating results, at a truly coastwide spatial scale for derived such a derived biocriterion.

\section{Conclusions}

The many different processes and effects of coastal eutrophication are well known and documented [51-53]. Numerous examples of watershed degradation leading to severe biological consequences are more and more common worldwide [54-57]. Many of the preceding examples document clearly many of the debilitating effects that excessive anthropogenic inputs can have on overall ecological health. In the present analysis, the absence of clear connections between degraded waterbodies and their biotic communities should not automatically be viewed as a constraint brought about by the techniques of this methodology, but rather could be thought as de facto verification that severely impaired waterbodies are not that common of an occurrence along the Texas coast, at least not when using nekton community structure as the indicator.

The assessment methodology used for this study was designed to capture community-level information on the richness and diversity of the tidal stream assemblages, both in terms of the number of species present and their states of phylogenetic relatedness. These methods were applied to the communities recorded by disparate gears, sampling very different parts of the overall tidal stream habitat. Both the seines (side of the stream, near-surface collections; youngof-the-year and juvenile stages) and otter trawls (middle of the stream, near-bottom collections; juvenile and subadult stages) generally recorded very similar, and very consistent communities, regardless of the "impairments" associated with each stream. All communities were dominated by a few taxa that each display tremendous euryhaline/physiological abilities. These abilities allow these taxa to adapt to a wide variety of salinity conditions. And it is because of these physiological abilities, few tidal stream organisms can truly be described as "sensitive." As such, the end result of the Assessment Methodology currently lacks the critical Index Development step. This step is predicated on "candidate taxa" that are sensitive to changes in the sometimes dramatic changes in the chemical or physical conditions found in tidally influenced ecosystems. As the mine canary can warn of the presence of a poisonous gas in a coal mine, the abundance or even presence of a few sensitive estuarine fishes could be used to document the early effects of waterbody degradation [58]. The downside to this approach is that management recommendations at the ecosystem-level could potentially be built upon the utmost weakest of foundations.

\section{Acknowledgments}

Funding for this project was provided by the Texas Commission on Environmental Quality in fulfillment of Contract 582-8-80180. Special thanks go to J. Leifester, L. Broach, and the many TPWD staff who participated in the Nueces River Trawl Survey. Additionally, the continued support of Sport Fish Restoration Funds enabled the time necessary for data synthesis and interpretation.

\section{References}

[1] B. C. Pease, "A spatially oriented analysis of estuaries and their associated commercial fisheries in New South Wales, Australia," Fisheries Research, vol. 42, no. 1-2, pp. 67-86, 1999.

[2] J. M. Tolan, "Larval fish assemblage response to freshwater inflows: a synthesis of five years of ichthyoplankton monitoring within Nueces bay, Texas," Bulletin of Marine Science, vol. 82, no. 3, pp. 275-296, 2008.

[3] R. P. Vasconcelos, P. Reis-Santos, A. Maia et al., "Nursery use patterns of commercially important marine fish species in estuarine systems along the Portuguese coast," Estuarine, Coastal and Shelf Science, vol. 86, no. 4, pp. 613-624, 2010.

[4] K. Wieski, H. Guo, C. B. Craft, and S. C. Pennings, "Ecosystem functions of tidal fresh, brackish, and salt marshes on the Georgia coast," Estuaries and Coasts, vol. 33, no. 1, pp. 161-169, 2010.

[5] TCEQ, "2010 Texas Integrated Report-Texas 303(d) List (Category 5)," The Texas Commission on Environmental Quality website, 2011, http://www.tceq.texas.gov/assets/public/compliance/monops/water/10twqi/2010_303d.pdf.

[6] D. Nicolas, J. Lobry, O. Le Pape, and P. Boët, "Functional diversity in European estuaries: relating the composition of fish assemblages to the abiotic environment," Estuarine, Coastal and Shelf Science, vol. 88, no. 3, pp. 329-338, 2010.

[7] C. Contreras, J. Nelson, and J. Tolan, "Proposed methodology for determining site-specific uses and criteria within tidally influenced portions of the River Basin and Coastal Basin waters of texas," Contract 582-2-48657, Texas Commission on Environmental Quality, 2005.

[8] TCEQ, “Texas Surface Water Quality Standards,” Tech. Rep. 307. 1-107. 10., 2000.

[9] S. Marshall and M. Elliott, "Environmental influences on the fish assemblage of the Humber estuary, UK," Estuarine, Coastal and Shelf Science, vol. 46, no. 2, pp. 175-184, 1998.

[10] A. McQuatters-Gollop, A. J. Gilbert, L. D. Mee et al., "How well do ecosystem indicators communicate the effects of anthropogenic eutrophication?" Estuarine, Coastal and Shelf Science, vol. 82, no. 4, pp. 583-596, 2009.

[11] D. Nicolas, J. Lobry, M. Lepage et al., "Fish under influence: a macroecological analysis of relations between fish species richness and environmental gradients among European tidal estuaries," Estuarine, Coastal and Shelf Science, vol. 86, no. 1, pp. 137-147, 2010.

[12] J. M. Tolan, "Coast-wide assessment of Texas tidal stream communities," Contract 582-8-80180, Texas Commission on Environmental Quality, 2008. 
[13] G. J. Guillen, Development of a rapid bioassessment method and index of biotic intergrity for tidal streams and bayous located along the Northwest Gulf of Mexico [Ph.D. thesis], Texas Natural Resource Conservation Commission, 1996.

[14] APA (Alan Plummer Associates), "Determination of aquatic life use classification nueces river tidal," Final Report, City of Corpus Christi, 1997.

[15] C. Contreras and A. Whisenant, "Cow bayou tidal (Segment 0511) use attainability analysis," Contract 582-2-48657, Texas Commission on Environmental Quality, 2007.

[16] J. Tolan, J. Nelson, N. Kuhn, and D. German, "Final report for determining site-specific uses and criteria within the tidally influenced portions of tres palacios river and garcitas creek," Contract 582-2-48657, Texas Commission on Environmental Quality, 2007.

[17] K. R. Clarke and R. M. Warwick, Change in Marine Communities: An Approach to Statistical Analysis and Interpretation, PRIMER-E, Plymouth, UK, 2nd edition, 2001.

[18] C. J. Walters and J. S. Collie, "Is research on environmental factors useful to fisheries management?" Canadian Journal of Fisheries and Aquatic Sciences, vol. 45, no. 10, pp. 1848-1854, 1988.

[19] A. Sosa-Lopez and D. Mouillot, "Spatiotemporal segregation regulates species richness along biomass gradients in estuarine fish assemblages," Marine Ecology Progress Series, vol. 342, pp. 217-226, 2007.

[20] N. M. Bacheler, L. M. Paramore, J. A. Buckel, and J. E. Hightower, "Abiotic and biotic factors influence the habitat use of an estuarine fish," Marine Ecology Progress Series, vol. 377, pp. 263-277, 2009.

[21] B. P. Piazza and M. K. La Peyre, "Nekton community response to a large-scale Mississippi River discharge: examining spatial and temporal response to river management," Estuarine, Coastal and Shelf Science, vol. 91, no. 3, pp. 379-387, 2011.

[22] J. A. Wiens, "Spatial scaling in ecology," Functional Ecology, vol. 3, no. 4, pp. 385-397, 1989.

[23] S. A. Levin, "The problem of pattern and scale in ecology," Ecology, vol. 73, no. 6, pp. 1943-1967, 1992.

[24] M. J. Kennard, J. D. Olden, A. H. Arthington, B. J. Pusey, and N. L. Poff, "Multiscale effects of flow regime and habitat and their interaction on fish assemblage structure in eastern Australia," Canadian Journal of Fisheries and Aquatic Sciences, vol. 64, no. 10, pp. 1346-1359, 2007.

[25] H. F. Wilson and M. A. Xenopoulos, "Landscape influences on stream fish assemblages across spatial scales in a northern Great Plains ecoregion," Canadian Journal of Fisheries and Aquatic Sciences, vol. 65, no. 2, pp. 245-257, 2008.

[26] M. A. Palmer, "Reforming watershed restoration: science in need of application and applications in need of science," Estuaries and Coasts, vol. 32, no. 1, pp. 1-17, 2009.

[27] G. A. Rose and W. C. Leggett, "The importance of scale to predator-prey spatial correlations: an example of Atlantic fishes," Ecology, vol. 71, no. 1, pp. 33-43, 1990.

[28] E. Núñez-Lara, J. E. Arias-González, and P. Legendre, "Spatial patterns of Yucatan reef fish communities: testing models using a multi-scale survey design," Journal of Experimental Marine Biology and Ecology, vol. 324, no. 2, pp. 157-169, 2005.

[29] H. Hillebrand, "Strength, slope and variability of marine latitudinal gradients," Marine Ecology Progress Series, vol. 273, pp. 251-267, 2004.
[30] T. D. Harrison and A. K. Whitfield, "Estuarine typology and the structuring of fish communities in South Africa," Environmental Biology of Fishes, vol. 75, no. 3, pp. 269-293, 2006.

[31] J. M. Tolan and J. M. Nelson, "Relationships among nekton assemblage structure and abiotic conditions in three Texas tidal streams," Environmental Monitoring and Assessment, vol. 159, no. 1-4, pp. 15-34, 2009.

[32] S. França, M. J. Costa, and H. N. Cabral, "Inter- and intraestuarine fish assemblage variability patterns along the Portuguese coast," Estuarine, Coastal and Shelf Science, vol. 91, no. 2, pp. 262-271, 2011.

[33] S. Akin, E. Buhan, K. O. Winemiller, and H. Yilmaz, "Fish assemblage structure of Koycegiz Lagoon-Estuary, Turkey: spatial and temporal distribution patterns in relation to environmental variation," Estuarine, Coastal and Shelf Science, vol. 64, no. 4, pp. 671-684, 2005.

[34] A. D. Jassby, W. J. Kimmerer, S. G. Monismith et al., "Isohaline position as a habitat indicator for estuarine populations," Ecological Applications, vol. 5, no. 1, pp. 272-289, 1995.

[35] E. J. Martino and K. W. Able, "Fish assemblages across the marine to low salinity transition zone of a temperate estuary," Estuarine, Coastal and Shelf Science, vol. 56, no. 5-6, pp. 969987, 2003.

[36] L. P. Rozas and C. T. Hackney, "Use of oligohaline marshes by fishes and macrofaunal crustaceans in North Carolina," Estuaries, vol. 7, no. 3, pp. 213-224, 1984.

[37] M. S. Peterson and S. T. Ross, "Dynamics of littoral fishes and decapods along a coastal river-estuarine gradient," Estuarine, Coastal and Shelf Science, vol. 33, no. 5, pp. 467-483, 1991.

[38] D. M. Baltz, C. Rakocinski, and J. W. Fleeger, "Microhabitat use by marsh-edge fishes in a Louisiana estuary," Environmental Biology of Fishes, vol. 36, no. 2, pp. 109-126, 1993.

[39] M. V. Ogburn Matthews and D. M. Allen, "Interactions among some dominant estuarine nekton species," Estuaries, vol. 16, no. 4, pp. 840-850, 1993.

[40] L. P. Rozas and T. J. Minello, "Restoring coastal habitat using marsh terracing: the effect of cell size on nekton use," Wetlands, vol. 27, no. 3, pp. 595-609, 2007.

[41] M. E. Pattillo, T. E. Czapla, D. M. Nelson, and M. E. Monaco, "Distribution and abundance of fishes and invertebrates in Gulf of Mexico estuaries, volume II: species life history summaries," ELMR Report no. 11, NOAA/NOS Strategic, Environmental Assessments Division, Silver Spring, Md, USA, 1997.

[42] H. Remmert, "Studies and thoughts about the zonation along the rocky shores of the Baltic," Zoologica, vol. 22, pp. 121-125, 1983.

[43] F. E. Clements, "Nature and structure of the climax," Ecology, vol. 24, pp. 252-284, 1936.

[44] H. Caswell, "Community structure: a neural model analysis," Ecological Monographs, vol. 46, pp. 327-354, 1976.

[45] R. J. Livingston, G. J. Kobylinski, F. G. Lewis III, and P. F. Sheridan, "Long-term fluctuations of epibenthic fish and invertebrate populations in Apalachicola Bay," Florida Fishery Bulletin, vol. 74, pp. 311-322, 1976.

[46] S. T. Ross, R. H. McMichael Jr., and D. L. Ruple, "Seasonal and diel variation in the standing crop of fishes and macroinvertebrates from a Gulf of Mexico surf zone," Estuarine, Coastal and Shelf Science, vol. 25, no. 4, pp. 391-412, 1987.

[47] T. P. Glancy, T. K. Frazer, C. E. Cichra, and W. J. Lindberg, "Comparative patterns of occupancy by Decapod Crustaceans in Seagrass, oyster, and marsh-edge Habitats in a Northeast Gulf 
of Mexico Estuary," Estuaries and Coasts, vol. 26, no. 5, pp. 12911301, 2003.

[48] W. D. N. Busch, M. Treadwell, L. Ross, and R. S. Jones, "A summary of progress and challenges in the use of an ecosystem-based approach for marine resource management," in Proceedings of the Mini-Symposium, p. 24, U.S. House of Representatives, Washington, DC, USA, 2002.

[49] L. A. Deegan, J. T. Finn, S. G. Ayvazian, C. A. Ryder-Kieffer, and J. Buonaccorsi, "Development and validation of an estuarine biotic integrity index," Estuaries, vol. 20, no. 3, pp. 601-617, 1997.

[50] K. A. Rose, "Why are quantitative relationships between environmental quality and fish populations so elusive?" Ecological Applications, vol. 10, no. 2, pp. 367-385, 2000.

[51] J. E. Cloern, "Our evolving conceptual model of the coastal eutrophication problem," Marine Ecology Progress Series, vol. 210, pp. 223-253, 2001.

[52] D. J. Conley, S. Markager, J. Andersen, T. Ellermann, and L. M. Svendsen, "Coastal eutrophication and the Danish National Aquatic Monitoring and Assessment Program," Estuaries, vol. 25, no. 4 B, pp. 848-861, 2002.

[53] C. Rönnberg and E. Bonsdorff, "Baltic sea eutrophication: areaspecific ecological consequences," Hydrobiologia, vol. 514, pp. 227-241, 2004.

[54] G. B. Jones, P. Mercurio, and F. Olivier, "Zinc in fish, crabs, oysters, and mangrove flora and fauna from Cleveland Bay," Marine Pollution Bulletin, vol. 41, no. 7-12, pp. 345-352, 2000.

[55] J. H. Andersen, L. Schlüter, and G. Aertebjerg, "Coastal eutrophication: recent developments in definitions and implications for monitoring strategies," Journal of Plankton Research, vol. 28, no. 7, pp. 621-628, 2006.

[56] F.-L. Xu, J.-Y. Hao, S. Tao, R. W. Dawson, K. C. Lam, and Y. D. Chen, "Restoration of marine coastal ecosystem health as a new goal for integrated catchment management in Tolo Harbor, Hong Kong, China," Environmental Management, vol. 37, no. 4, pp. 540-552, 2006.

[57] E. Padmini and B. V. Geetha, "A comparative seasonal pollution assessment study on Ennore Estuary with respect to metal accumulation in the grey mullet, Mugil cephalus," Oceanological and Hydrobiological Studies, vol. 36, no. 4, pp. 91-103, 2007.

[58] T. Clark, K. Clark, S. Paterson, D. Mackay, and R. J. Norstrom, "Wildlife monitoring, modeling, and fugacity," Environmental Science and Technology, vol. 22, no. 2, pp. 120-127, 1988. 

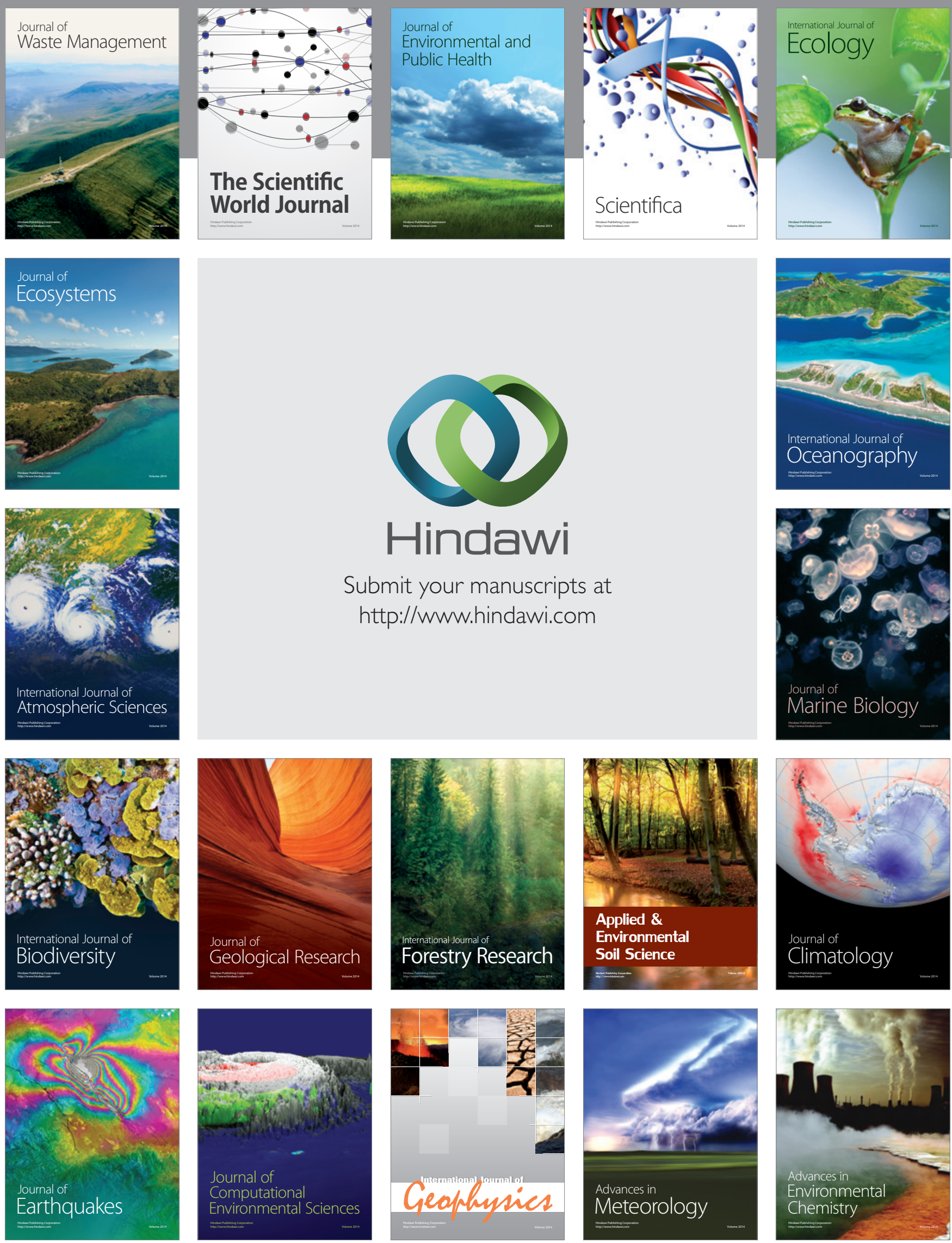